\title{
Impact of Government Budget Announcement on Stock Market Sector Indices: Evidence from Colombo Stock Exchange
}

\author{
Udani Chathurika Edirisinghe \\ Department of Accountancy \& Finance, Faculty of Management Studies, Sabaragamuwa University of Sri Lanka, Belihuloya, Sri Lanka
}

Email address:

chathurikaedirisinghe@gmail.com

\section{To cite this article:}

Udani Chathurika Edirisinghe. Impact of Government Budget Announcement on Stock Market Sector Indices: Evidence from Colombo Stock Exchange. Journal of Finance and Accounting. Vol. 5, No. 6, 2017, pp. 214-218. doi: 10.11648/j.jfa.20170506.12

Received: MM DD, 2017; Accepted: MM DD, 2017; Published: MM DD, 2017

\begin{abstract}
This study attempts to investigate the impact of Sri Lankan government budget announcements on five sector indexes of Colombo Stock Exchange, namely banks, finance \& insurance; beverage, food \& tobacco; manufacturing; motor; diversified holdings. The Event study methodology was used to analyze sector wise stock price behavior during the sample period of 2002 to 2013. Results revealed that although the overall trend of the average returns of each sector around budget announcements are same the magnitude of the reaction is different from sector to sector. Motor was the mostaffected sector and diversified holdings sector was the least affected.
\end{abstract}

Keywords: Government Budget, Sector Indexes, Average Returns

\section{Introduction}

Government budget announcement would be a most awaited event by many parties/people in a country because it defines the financial road map of the country for the preceding year. The governing body of the country, to meet its objectives of reaching economic stability and growth execute numerous policies. These policy implementations involve humongous fund utilization in different sectors such as defense, administration, and development, and welfare. The annual budget is the formal announcement by the government on the fund allocations and the tax policy changes, as it is the main source of government income.

A budget is an influential instrument which offers the legitimate power to the government to control the fiscal resources of the country [7] In Sri Lanka Department of National Budget (DNP) is the authorized body to prepare the budget by coordinating all the government ministries under a government. According to the tentative budget calendar, during the third week of September the appropriation bill is submitted to the parliament and during the first week of November Minister of Finance declares the budget speech in the parliament [13]. Date of the budget speech is one of the most awaiting political events in the country, as it will illustrate the government income and expenditure for proceeding year. But most importantly the policy decisions announced through the budget speech can be stimulating or discouraging to companies listed on the Colombo Stock Exchange (CSE). Consequently, the investors of listed companies would react to these policy decisions depending upon their effect on different industries. Thus the objective of this study is to analyze the stock price reaction to budget announcements of five selected sector indices of Colombo Stock Exchange by utilizing event study methodologies. Although there have been studies carried out to analyze the stock market reaction to budget announcements these studies have been analyzing the overall effect to the market and rarely focused on sector-wise analysis. Hence current study would contribute to filling this gap in the literature.

\section{Literature Review}

Stock Market reaction to government budget announcement has been widely discussed topic and many related studies could be identified all around the world. Most of these studies have been a concern with investigating the volatility of the stock market during pre and post budget period. Varadharajan and Vikkraman [15] find that in four 
major indices of Indian stock market, post-budget volatility in the stock market is higher in comparison to pre-budget volatility. Thomas and Shah [14] stated that activities of the stock market are greatly influenced by the union budget and the budget has been often viewed as an important summary statistic to reflect the quality of governments' strategies in terms of contribution to macroeconomic development. Many past studies have focused on the reaction to thebudget announcement in the different span of periods, i.e. short term, medium term and longer terms. Gupta and Kundu [5] have found that in India maximum impact of union budget is in the short-termpost-budget period compared to medium term and long term because post-budget average returns do not tend to generally increases as time passes. Khanna and Gogia [7] have conducted a multi-country study on the impact of budget announcements covering India, USA, and the UK. They have observed similar findings to Gupta and Kundu [5] where Indian Stock Markets are mainly affected in short-term and somewhat in the medium term. But in the USA the effect of the federal budget is more in long-term and medium term because in the USA it takes along period for the budget to be approved by the Congress and to be in effect and investors react to the views given by market analysts during this time. Similar to India, UK also tends to react in short and medium term, mainly observing high anxiety about budget announcements during the period close to Budget day. Gakhar, Kushwaha and Ashok [4] also finds similar results in India evidencing the maximum impact of the budget in shortterm and gradually decreasing in the medium term, and eventually diminishing in the long run. Ranjani, Sujeewa and Rathnasiri [12] has conducted an event study to investigate the effect of government budget announcement on CSE and have observed that there is an upward trend in the market reaction to the years which include tax concessions and exceptions.

Budget reaction to monetary and fiscal policy announcements also have been a subject of many studies. Leiderman and Offenbacher [9] depict that unexpected monetary policy announcements have a significant positive impact on Stock prices in Israel. Bernanke and Kuttne [2] also conclude similar findings stating unanticipated monetary policy actions have resulted with expected excess return accounts. A study conducted by Andritzky, Bannister and Tamirisa [1] to measure the impact of macroeconomic announcements on emerging bond markets reveals that the effect of the announcement is lesser in countries with more transparent policies and higher credit ratings. Hussain [6] confirms that European and US stock markets have an immediate and significant influence on stock index returns and volatility, for monetary policy decisions and macroeconomic news announcements.

Although it is rare to find studies focusing on budget announcements to different sectors in the stock market, acouple of studies have covered this area. Mohanty [11] have conducted an event study to analyze the reaction to various policy announcements to telecom sector, banking and financing sector and pharmaceutical sector and conclude that stocks react to public news quite quickly but the first adjustment may not always be accurate. Kutchu [8] who analyses the effect of union budget to six sector indices justifies that impact of budgeted cannot be distinguished to a particular sector but could be recognized company specific reactions.

\section{Data and Methodology}

Event study methodology was mainly adopted to reach the objective of the study. One of the important data items for this analysis tool is the event date. Although there is a number of days in the budget calendar, the budget speech day (the day minister of the finance presenting the budget to the parliament) is the day which makes the budget published. Thus this date has been considered as the event date. The sample period of the study is from 2002 to 2013, evidencing 12 budget speeches, i.e. 12 events. The study considered 150 days as the estimation period and 60 days and the event period (30 days prior and 30 days post to the events) resulting with 181 days in the event window.

There are 295 companies listed in the CSE as at $14^{\text {th }}$ July 2017 representing 20 business sectors. Five sectors have been selected for the study, namely Banks, Finance \& Insurance (BFI), Beverage, Food \& Tobacco (BFT), Manufacturing (MFG), Motor (MTR), Diversified Holdings (DIV). BFI, BFT, and DIV sectors were selected because they are the sectors with the highest market capitalizations, MFG sector is the sector with the highest number of listed companies and the MTR sector was selected with the assumption that the frequent tax policy changes for imported automobiles may have an effect on this sector.

Abnormal returns are the difference between the observed return of firm $\mathrm{i}$ and the expected return generating by a benchmark model.

$$
\mathrm{AR}_{\mathrm{it}}=\mathrm{R}_{\mathrm{it}}-\mathrm{E} \text { (Rit) }
$$

$\mathrm{AR}_{\mathrm{it}}=$ Abnormal Returns of Firm $\mathrm{i}$ on event $\mathrm{t}$

$\mathrm{R}_{\mathrm{it}}=$ Normal Returns of Firm $\mathrm{i}$ on event $\mathrm{t}$

$\mathrm{E}_{(\mathrm{Rit})}=$ Expected Return/Normal Returns of the sector $\mathrm{i}$ on event $\mathrm{t}$

In order to calculate expected returns during the event period of the day -30 to day +30 study uses Market Model (MM). Expected return is defined as,

$$
\mathrm{E}\left(\mathrm{R}_{i t}\right)=\alpha_{\mathrm{i}}+b_{i}\left(\mathrm{R}_{\mathrm{mt}}\right)
$$

Where $\alpha_{i}$ and $b_{i}$ are coefficient estimates of the linear relationship between sector i's daily stock returns taken from the daily returns files of CSE data library and the daily returns of the All Share Price Index (ASPI) of CSE.

Results of the study can be greatly improved by averaging the information over all the years subjected to the analysis. Thus, the cross-sectional Average of Abnormal Returns (AAR) and Cumulative Average Abnormal Returns (CAAR) for the stocks were calculated.

The statistical significance of the event period abnormal 
return was assessed for the sample based on the model used for predicting abnormal return.

The null hypothesis and the alternative hypothesis for CAAR are set as follows;

$\mathrm{H}_{\mathrm{b} 0}=$ Mean day ' 0 ' Cumulative Average abnormal return is equal zero

$\mathrm{H}_{\mathrm{b} 1}=$ Mean day ' 0 ' Cumulative Average abnormal return is not equal zero

The standard test statistic is the AAR or CAAR divided by standards error (standard deviation divided by square root of $\mathrm{N})$. This method of statistical significance test has been widely used in previous studies $[3,10]$.

The test statistic of AAR at any event day $t$ is,

$$
\frac{A R R_{t}}{\sigma_{A R} / \sqrt{n}}
$$

$\mathrm{ARR}_{\mathrm{t}=}$ The average abnormal return for time $t$

$\sigma_{A R}=$ The standard deviation of abnormal returns at time $\mathrm{t}$ $\mathrm{n}=$ The sample size/number of returns

Test statistic of CAAR for event period $t_{1}$ to $t_{2}$ :

$$
\frac{C_{C A R R} t}{\sigma_{C A R} / \sqrt{n}}
$$

$\mathrm{CARR}_{\mathrm{t}}=$ The cumulative average abnormal return for time $t$ $\sigma_{C A R}=$ The cross sectional standard deviation of abnormal returns at time $\mathrm{t}$

$$
\mathrm{n}=\text { The sample size/number of returns }
$$

\section{Results}

This section of the paper illustrates the findings of the study. Table 1 illustrates the CAAR and their statistical significance at 5 percent confidence level for the even window day -10 to day +10 . The day 0 CAAR for the sector BFI, BFT, MFG, MTR, DIV respectively are -1.31 percent, 3.13 percent, -6.35 percent, -8.14 percent, 0.05 percent respectively. Since the CAAR on day 0 of all the sectors are not equal to zero, thus have to accept the alternative hypothesis which concludes the day 0 CAAR is not equal to zero. The sector with the highest CAAR is MTR $(-8.14$ percent) and the sector with the lowest CAAR is DIV and the CAAR of that sector is just. 05 percent which is almost equal to zero but unlikely as other sectors the statistical significance of this sector is low which does not confirm the

\begin{tabular}{|c|c|c|c|c|c|c|c|c|c|c|}
\hline \multirow[b]{2}{*}{ Days } & \multicolumn{2}{|l|}{ BF I } & \multicolumn{2}{|c|}{ Food \& Beverage } & \multicolumn{2}{|c|}{ Manufacturing } & \multirow{2}{*}{$\begin{array}{l}\text { Motor } \\
\text { CAAR }\end{array}$} & \multicolumn{3}{|c|}{ Diversified } \\
\hline & CAAR & T-stat & CAAR & T-stat & CAAR & T-stat & & T-stat & CAAR & T-stat \\
\hline-10 & $0.03 \%$ & 0.13 & $-2.89 \%$ & -10.76 & $-4.47 \%$ & -17.71 & $-4.48 \%$ & -9.79 & $0.16 \%$ & 0.828 \\
\hline-9 & $0.04 \%$ & 0.17 & $-2.39 \%$ & -4.03 & $-4.23 \%$ & -6.15 & $-5.15 \%$ & -11.29 & $-0.18 \%$ & -0.612 \\
\hline-8 & $0.27 \%$ & 2.00 & $-2.99 \%$ & -6.80 & $-4.58 \%$ & -8.41 & $-6.00 \%$ & -9.38 & $-0.09 \%$ & -0.384 \\
\hline-7 & $0.06 \%$ & 0.36 & $-3.02 \%$ & -12.88 & $-4.50 \%$ & -16.89 & $-6.09 \%$ & -6.38 & $-0.30 \%$ & -1.15 \\
\hline-6 & $-0.15 \%$ & -1.25 & $-3.31 \%$ & -15.83 & $-4.71 \%$ & -20.25 & $-6.30 \%$ & -11.22 & $-0.23 \%$ & -1.035 \\
\hline-5 & $-0.41 \%$ & -2.28 & $-3.38 \%$ & -14.95 & $-5.12 \%$ & -13.89 & $-5.91 \%$ & -12.78 & $-0.32 \%$ & -1.061 \\
\hline-4 & $-0.86 \%$ & -3.04 & $-3.84 \%$ & -7.19 & $-5.78 \%$ & -10.49 & $-6.52 \%$ & -12.33 & $-0.05 \%$ & -0.158 \\
\hline-3 & $-0.87 \%$ & -2.14 & $-3.32 \%$ & -11.32 & $-5.72 \%$ & -14.05 & $-6.94 \%$ & -25.18 & $-0.04 \%$ & -0.279 \\
\hline-2 & $-0.77 \%$ & -2.73 & $-3.68 \%$ & -10.25 & $-6.27 \%$ & -19.29 & $-6.90 \%$ & -15.61 & $0.53 \%$ & 1.324 \\
\hline-1 & $-1.13 \%$ & -6.16 & $-3.25 \%$ & -6.79 & $-6.31 \%$ & -11.25 & $-7.18 \%$ & -17.06 & $0.42 \%$ & 2.138 \\
\hline 0 & $-1.31 \%$ & -7.93 & $-3.13 \%$ & -6.30 & $-6.35 \%$ & -25.51 & $-8.14 \%$ & -10.53 & $0.05 \%$ & 0.228 \\
\hline 1 & $-1.43 \%$ & -7.77 & $-3.05 \%$ & -16.39 & $-6.48 \%$ & -20.87 & $-7.13 \%$ & -9.21 & $0.30 \%$ & 1.822 \\
\hline 2 & $-1.60 \%$ & -8.60 & $-3.03 \%$ & -8.73 & $-7.03 \%$ & -17.98 & $-7.79 \%$ & -16.63 & $0.33 \%$ & 2.132 \\
\hline 3 & $-1.82 \%$ & -7.26 & $-3.33 \%$ & -20.94 & $-7.15 \%$ & -34.69 & $-8.72 \%$ & -16.87 & $0.55 \%$ & 3.214 \\
\hline 4 & $-1.70 \%$ & -7.73 & $-3.40 \%$ & -11.15 & $-6.99 \%$ & -17.00 & $-9.37 \%$ & -21.93 & $0.38 \%$ & 1.671 \\
\hline 5 & $-1.80 \%$ & -8.33 & $-3.47 \%$ & -14.48 & $-6.70 \%$ & -29.67 & $-9.93 \%$ & -16.71 & $0.21 \%$ & 1.199 \\
\hline 6 & $-2.05 \%$ & -12.81 & $-3.59 \%$ & -8.46 & $-7.12 \%$ & -22.29 & $-8.69 \%$ & -15.44 & $0.14 \%$ & 0.883 \\
\hline 7 & $-2.03 \%$ & -15.56 & $-3.60 \%$ & -13.58 & $-7.37 \%$ & -16.58 & $-9.23 \%$ & -26.22 & $-0.03 \%$ & -0.089 \\
\hline 8 & $-2.51 \%$ & -12.13 & $-3.86 \%$ & -14.64 & $-7.35 \%$ & -30.45 & $-10.12 \%$ & -13.17 & $-0.10 \%$ & -0.655 \\
\hline 9 & $-2.49 \%$ & -13.35 & $-4.11 \%$ & -29.75 & $-7.89 \%$ & -28.38 & $-9.86 \%$ & -20.02 & $-0.31 \%$ & -2.041 \\
\hline 10 & $-2.54 \%$ & -14.42 & $-4.24 \%$ & -13.58 & $-7.80 \%$ & -34.16 & $-10.28 \%$ & -29.14 & $-0.52 \%$ & -2.797 \\
\hline
\end{tabular}
validity of the findings at the population level.

Table 1. CAAR from day -10 to Day +10 for selected Sector Indices.

Source: CSE data library.

The sector-wise CAAR of day -10 to +10 is further interpreted in order to obtain a more in-depth view on the behavior of each sector around budget announcements. In BFI sector the CAAR starts to turn negative from 6 days prior to the budget announcement and can assume that this is the day which the sector starts reacting to anticipated changes in the budget announcements, specifically being a sector which is more sensitive to monetary policy changes. CAAR behavior of BFT and MFG sectors are more different, where those sectors CAAR starts to turn negative and continue to do so from day -25 which means almost a month prior to the budget announcements. This behavior cannot be explained exactly whether being due to the budget announcements or not. MTR sector is the sector which is showing a negative CAAR trough out the event window starting from the day -30 but it can be specifically noticed that in this sector the negative trend in the CAAR becoming more severe after the budget announcements. From all the sectors selected DIV is the sector which shows an entirely different scenario with having positive CAAR on most of the days in the event window and can recognize that the budget announcement may have a profound effect on this sector performance 
because CAAR turns positive from Day -3 and continue to do so until seven days after the event day. In addition to the above analysis, the CAAR behavior of each sector throughout the event window (day -30 to Day +30 ) are graphically illustrated to identify the sector-wise difference.

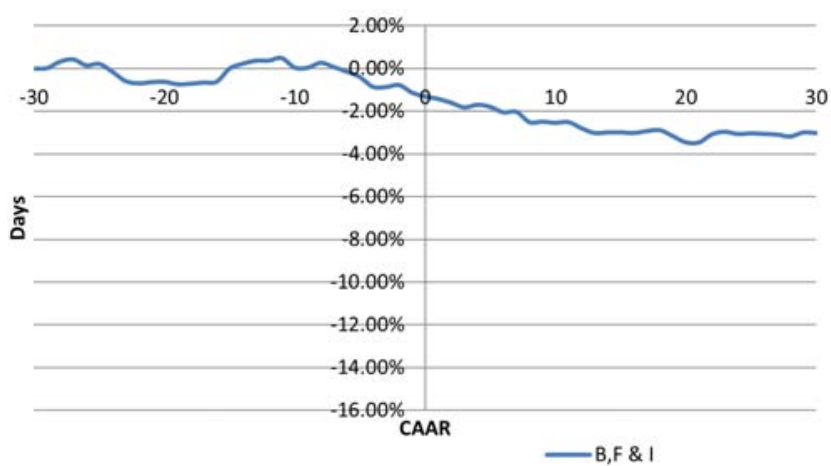

Figure 1. Pre and Post Budget CAAR Behaviour of Banking Finance and Insurance Sector.

Figure 1 illustrates the behavior of CAAR in 30 days pre and post budget period. Throughout the even window, returns are predominately negative apart from the period day -29 to day -24 and day -15 to day -7 . The overall trend of the CAAR is also downward. The negative CAAR starts in this sector on Day -6 which implies that this sector starts to react negatively 6 days before the announcement day and the same trend continues with increasing proximity throughout the post-event period.

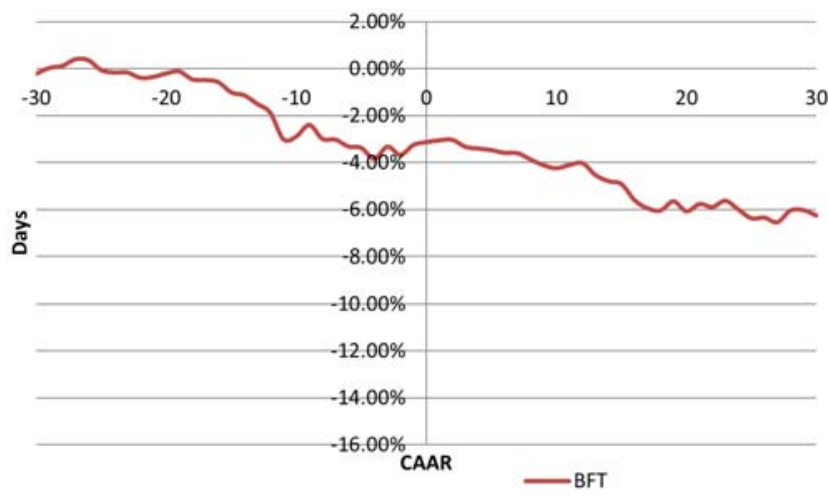

Figure 2. Pre and Post Budget CAAR Behaviour of Beverage, Food \& Tobacco Sector.

According to Figure 2 the CAAR behavior of BFT sector shows that stock prices react negatively to the budget announcement during pre and post budget periods. The negative CAAR starts from day -25 and continue to do so with slight fluctuations throughout the even period. But there is a marginal decrease in the negative CAAR immediately after the event day (on day +1 and day +2 ) but again slope of the negative CAAR increases after day +3 and it steepens more than the pre-event period.

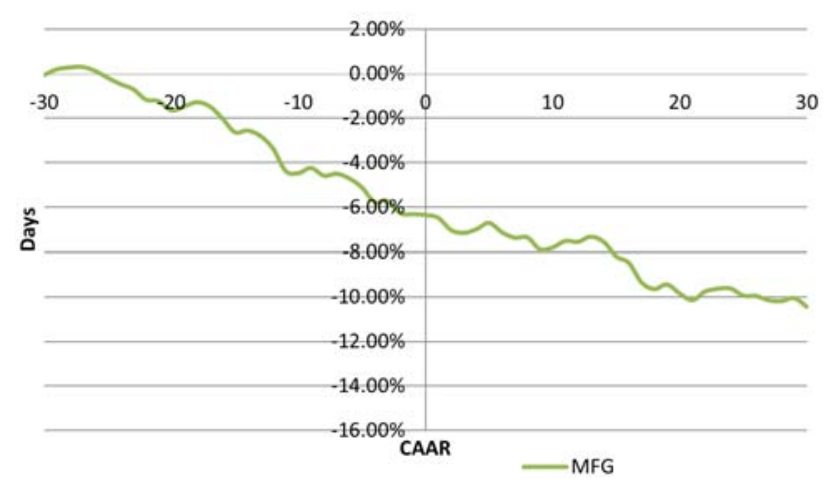

Figure 3. Pre and Post Budget CAAR Behaviour of Manufacturing Sector.

CAAR trend of MFG sector also shows a similar trend as the previous sector as illustrated in Figure 3. After day -26 the excess returns continue to be negative until Day +30 . It seems that MFG sector reacts negatively before and after the budget announcements. At Day 0 the CAAR is -6.35 percent and the reaction after the announcement continues the preannouncement reaction and by day +30 it hits the lowest CAAR, which is -10.44 per cent.

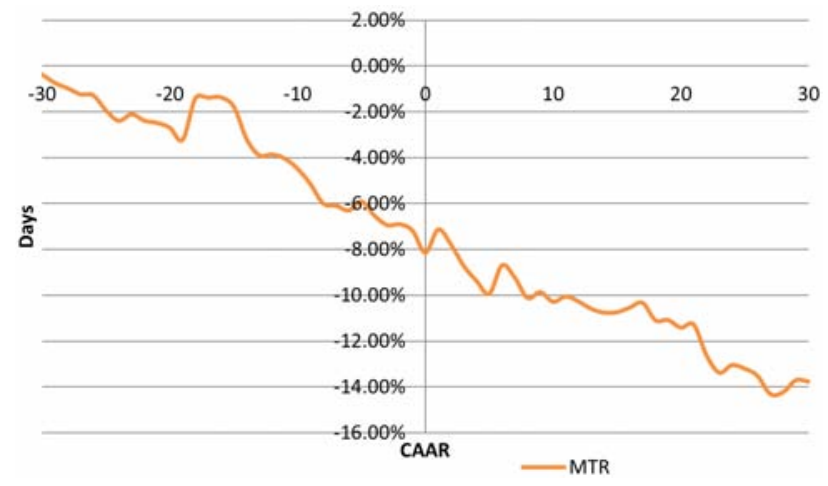

Figure 4. Pre and Post Budget CAAR Motor Sector.

As illustrated in Figure 4 the CAAR behavior of MTR sector is similar to the MFG sector. With slight fluctuations, CAAR throughout the event window is negative and increasing over the 60 days and the slope of CAAR behavior is steeper than the slope of the previous sector. But on the event day (day 0) the CAAR is -8.00 percent and it slightly increases to -7.13 percent, but beyond that, the negative trend continues.

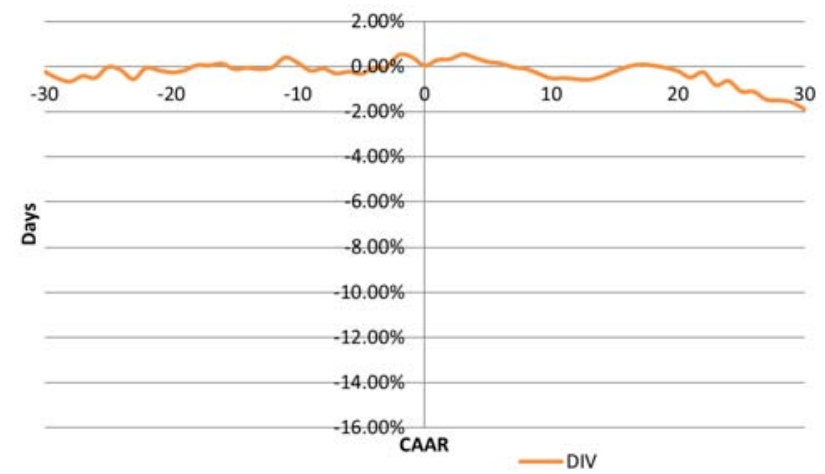

Figure 5. Pre and Post CAAR behavior of the Diversified Sector. 
Compared to other sectors the CAAR behavior of DIV sector is only fluctuating within the range of 1 percent to -2 percent. Even though CAAR throughout the event period is predominately negative, fluctuations of the negative CAAR are marginal. It is noticeable that this is the only sector with CAAR almost equal to 0 percent on the event day (Day 0) and immediately after the budget announcements and until day 7 the sector shows positive CAAR, again a reaction contrasting compared to other sectors.

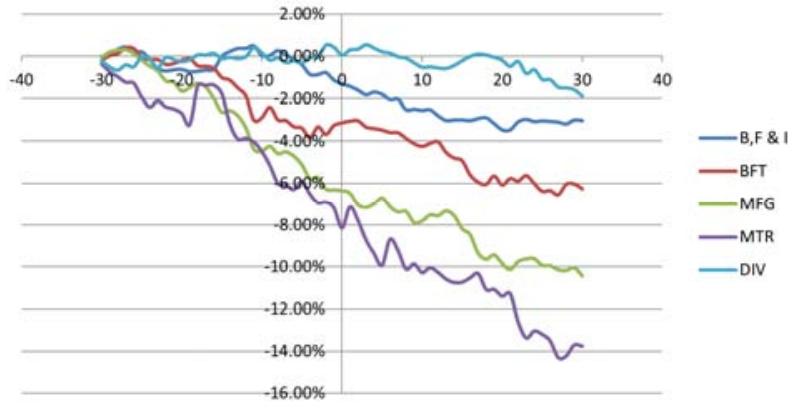

Figure 6. Sector CAAR Behavior.

Figure 6 shows the CAAR behavior of all five sectors in comparison with each other. It is evident that MTR sector is the most affected sector since the negative CAAR during the post-event window of the motor sector is higher than rest of the sector. Next, most affected sector is MFG sector followed by the BFT sector, least effected two sectors are BFI and DIV. Regardless, all the sectors have negative CAAR throughout the event window with little exceptions in the early days of the pre-event window.

\section{Conclusion}

This study provides important empirical evidence on sectorwise reaction of stock exchange for government budget announcements. Majority of the previous studies measures the overall impact to the stock market but not on the sector-wise impact, thus current study attempt to fill this research gap. Out of 20 sectors in the CSE 5 sectors were selected for this study justifying the importance of each sector. Data period for the study is 2002 to 2013 considering 12 budget announcements. Event study methodology was mainly employed to analyze the pre and post budget impact on sector indices. The results show that all 5 sectors have increasing negative CAAR throughout the pre and post event windows but the proportions of these negative CAAR trends are different from one sector to another. DIV is the least affected sector and Motor is the most affected sector. The latter is not a Mystery as every year's government budget involve fiscal policy changes related to imports of the automobile, since it is one of the main tax incomes of government. But the reaction of BFI sector (second least affected sector) is surprising as changes to the monetary policies are also an essential element is the budget announcement which would directly affect to Sri Lankan financial Institutions and markets. The effect on DIV sector may be minimal because this sector consists of companies which have investments diversified among many industries in the economy, thus effect may have spread across all the sectors involved. Finally, it can be concluded that although in all five sectors the general reaction to the budget announcement is negative the magnitude of these reactions are different from sector to sector

\section{References}

[1] Andritzky, J. R., Bannister, G. J., \& Tamirisa, N. T. (2007). The impact of macroeconomic announcements on emerging marketbonds. Emerging Markets Review, 8 (1), 20-37.

[2] Bernanke, B. S., \& Kuttner, K. N. (2005). What explains the stock market's reaction to Federal Reserve policy?. The Journal of finance, 60 (3), 1221-1257.

[3] Brown, S. J. \& Warner, J. B. (1985), Using daily stock returns - the case of event studies, Journal of Financial Economics, $14,3-31$.

[4] Gakhar, D. V., Kushwaha, N., \& Ashok, V. (2015). Impact Of Union Budget On Indian Stock Market. Scholedge International Journal of Management \& Development ISSN 2394-3378, 2 (11), 21-36.

[5] Gupta, A., \& Kundu, D. (2006). A Study on the Impact of Union Budgets on Stock Prices in India. The ICFAI Journal of Applied Finance, 12 (10), 65-76.

[6] Hussain, S. M. (2011). Simultaneous monetary policy announcements and international stock markets response: An intraday analysis. Journal of Banking \& Finance, 35 (3), 752-764.

[7] Khanna, K., \& Gogia, N. (2014). A Pragmatic Study of Budget Announcements \& Stock Market Performance: India, US \& UK Panorama. VSRD International Journal of Business and Management Research, 4.

[8] Kutchu, V. (2012). Testing semi-strong efficiency of Indian stock market-A study on effect of union budget 2012 on six select sectoral stocks. Researchers World, 3 (3), 74.

[9] Leiderman, L., \& Offenbacher, E. K. (1986). Monetary announcements and stock prices in Israel. Economics Letters, 20 (4), 377-381.

[10] Masulis, R. W. (1980), The effects of capital structure change on security prices: a study of exchange offers, Journal of Financial Economics, 8 (2), 139-178.

[11] Mohanty, M. (2004). Stock Market Reaction to Announcement of Policy Changes. The ICFAI Journal of Applied Finance, 34-42.

[12] Ranjani, R. C., Sujeewa, G. M., \& Rathnasiri, U. A. H. A. (2009). The impact of the government budget announcement on Colombo Stock Exchange. Research Symposium 2009Faculty of Graduate Studies, University of Kelaniya.

[13] Sarvananthan, M. (2007). The Government Budget: A Critical Appraisal with Reference to Transparency and Accountability, Pathfinder Foundation Colombo, Sri Lanka.

[14] Thomas, S., \& Shah, A. (2002). Stock market response to Union Budget. Economic and Political weekly, 455-458.

[15] Vandhanjan, P., \& Vikkraman, P. (2011). Impact of Pre and Post Budget on Stock Market Volatility Between 2001 to 2011. Journal of Contemporary Research in Management, 6 (4), 49. 